\section{The relationship between levels of income inequality and dental caries and periodontal diseases}

\author{
A associação dos níveis de desigualdade de renda \\ com cárie dental e doença periodontal
}

\author{
${ }^{1}$ Faculdade de Odontologia, \\ Universidade Federal do Rio \\ Grande do Sul, Porto Alegre, \\ Brasil. \\ 2 Centre for Health Equity \\ Studies, Stockholm University/ \\ Karolinska Institutet \\ Stockholm, Sweden. \\ 3 Instituto de Medicina Social \\ Universidade do Estado do \\ Rio de Janeiro, Rio de Janeiro, \\ Brasil. \\ Correspondence \\ R. K. Celeste \\ Departamento de Odontologia \\ Preventiva e Social, Faculdade \\ de Odontologia, Universidade \\ Federal do Rio Grande do Sul. \\ Rua Ramiro Barcelos 2492, \\ sala 301, Porto Alegre, \\ RS 90035-030, Brasil. \\ roger.keller@ufrgs.br
}

\section{Abstract}

The objective of this study was to evaluate the association between income inequality at a lagged time of 2 and 11 years with two short latency outcomes (untreated dental caries and gingivitis) and two long latency outcomes (edentulism and periodontal attachment loss $>8 \mathrm{~mm}$ ). We used data from the Brazilian oral health survey in 2002-2003. Our analysis included 13,405 subjects aged 35-44 years. Different lagged Gini at municipal level were fitted using logistic and negative binomial multilevel analyses. Covariates included municipal per capita income, equivalized income, age, sex, time since last dental visit and place of residence (rural versus urban). Crude estimates showed that only untreated dental caries was associated with current and lagged Gini, but in adjusted models only current Gini remained significant with a ratio of 1.19 (95\%CI: 1.09-1.30) for every ten-point increase in the Gini coefficient. We conclude that lagged Gini showed no association with oral health; and current income Gini was associated with current dental caries but not with periodontal disease.

Periodontal Diseases; Dental Caries; Social Inequity
Roger Keller Celeste 1

Johan Fritzell 2

Paulo Nadanovsky 3

\section{Introduction}

There has long been a debate on whether income inequality has an effect on health 1,2 . Despite many reviews, some containing more than a hundred studies, no consensus has been reached $3,4,5,6,7,8$. It seems that if the specific mechanisms by which income inequality works are not well understood, this debate will remain unresolved. Conflicting results may be due to differences of aggregation at the geographical level and/or the variables used to control for confounding 5 . Of course, different conclusions may also follow from variations in the specific health outcome studied. One approach that might be crucial, but tends to be neglected, is the comparison of the effects of income inequality at different time lags 6,9. Moreover, due to differences in disease latency, these time lags should vary for different health outcomes.

Studies evaluating time lags between income inequality and health have obtained different results. Blakely et al. 10 suggested that exposure to income inequality 15 years before the outcome - perhaps throughout this time if exposure levels did not vary - could be more important than contemporary income inequality for self-rated health. A similar result was shown by Subramanian et al. 11, who presented a gradual increase in the odds ratio of having poor self-rated health as the lag time increased. On the other hand, Mellor 
\& Milyo ${ }^{12}$ found weak evidence for the effect of a 15 year time lag when searching for lags between 5 and 29 years. In addition, another study put together Gini coefficients for lags of 25, 15 and 5 years, but only the latter showed a significant relationship ${ }^{9}$. A European study provided further evidence on time lags, associating the Theil Index and the infant mortality rate among 16 wealthy countries 13 . In that study, all time lags showed a significant relationship with infant mortality, but the strongest relationship was with contemporary Theil, implying an immediate effect of income inequality. Regarding neonatal death, the current Gini effect was reported to be greater than the effect for five years earlier 14 .

Some unclear issues are present in previous studies. For example, despite claims that it is implausible for income inequality to act instantaneously 10,11, some outcomes associated with it, like homicides 15 and infant mortality 13, do not have long latency. Therefore, it seems plausible that income inequality may have short and long time (i.e. cumulative) effects. It has been argued that the use of outcome-specific associations should be more informative than the often-used self-rated health, life expectancy or total mortality, as these mix different disease pathways 6 . Finally, it has been suggested that income inequality may have lagged effects on oral health 16 , an issue not well explored.

Although there are some studies on the effect of income inequality on dental caries, to our knowledge there are none on its effect on periodontal diseases at individual level. At the contextual level, income inequality (measured by the Gini coefficient) may be a proxy for individual level comparisons across income strata. Regarding periodontal disease, people at the lower end of the income scale may suffer the effect of comparisons through stress induced behaviour (toothbrushing) and neuroendocrine pathways, with higher levels of cortisol and deficient immune response 3 . Although the issue has not been resolved, there seems to be strong evidence linking stress and other psychosocial factors to periodontal diseases 17,18. The relation between dental caries and income inequality may be explained by oral health behaviours that change under stressful situations, such as diet (sugar consumption) and oral hygiene (with fluoridated toothpaste). In addition, lack of coping abilities have been associated with tooth loss 19. Another pathway linking income inequality and oral health in general points out that high income inequality is associated with under-investment in public policy ${ }^{3}$, including the delivery of (dental) health services 13 .

\section{Latency time of oral diseases - a priori} hypotheses

Latency can be defined as the time from the beginning of a disease until its diagnosis 20 . For oral, and other chronic diseases to occur, the individual must be exposed to risk factors for a period of time (induction time) up to a level that irreversibly leads to the disease. After this period, the preclinical phase of the disease follows, when signs or symptoms are not detectable (latent period). The lag time includes the latency time along with all or part of the induction duration. The latency time varies from disease to disease and when the timing of diagnosis changes (at an earlier or later stage of the disease development), but the induction is a property of the exposure.

If income inequality is to influence oral diseases, then the timing of the exposure (at the end of the induction time) should match the disease latency. For instance, it is implausible that current exposure would be causally associated with an outcome of long latency, since there is not enough time for the disease development; the exception to this is when exposure is constant over time. On the other hand, if current income inequality is associated with a disease of short latency, cumulative exposure should be associated with a cumulative measure of the same disease.

In the present study, two short-latency oral diseases, as well as their long-term counterparts, were selected. The hypothesis is that if current income inequality has an effect on current disease (untreated dental caries/gingivitis), then the cumulative exposure will be associated with a cumulative measure of the disease (edentulism/ periodontal attachment loss).

Regarding dental decay, if cavities due to dental caries are left untreated, they can lead to tooth loss and eventually edentulism. Dental caries seems to be the direct reason for more than $70 \%$ of tooth extraction, at least in one major Brazilian capital 21 . The incidence of dental caries appears to be stable throughout a person's lifespan if no effort is made to control its progression ${ }^{22}$. Clinically detectable dentine lesions in children have been estimated to take a median time of around four to seven years to develop 23,24 . In comparison, for an individual to lose all his/her teeth (i.e. edentulism) it would normally take decades.

Concerning periodontal diseases, gingivitis (i.e. gum bleeding due to bacterial dental plaque, characterizing chronic inflammation) takes around two to three weeks to develop if oral hygiene is refrained from 25 . If the gingival chronic inflammation is left, some teeth sites may develop periodontitis, characterized by irreversible alveo- 
lar bone loss. Recent evidence of untreated sites of periodontitis among adults showed that bone loss progressed at $1 \mathrm{~mm}$ per 8.4 months on average 26 . The time it takes for gingivitis to progress to periodontitis is unknown and could take years; however, gingivitis is a necessary condition.

The aim of this study is to evaluate the association of income inequality at lagged time of 2 and 11 years with two short-latency outcomes (untreated dental caries and gingivitis) and with two long-latency outcomes (edentulism and periodontal attachment loss $>8 \mathrm{~mm}$ ).

\section{Methods}

\section{Data source}

Data from a national oral health survey carried out in 2002-2003 (SBBrasil) by the Brazilian Ministry of Health were used as the source of the oral health outcomes and individual level covariates. The original sample consisted of 108,921 individuals in seven different age groups, randomly chosen in a multi-stage sampling frame from 250 municipalities. A detailed description of sampling techniques is available elsewhere 27 . Unfortunately, representativeness of the original sample is not assured by design, as sampling fractions are unknown ${ }^{28}$. We believe that this is not a problem for our purposes, as we are interested in associations. The present analysis included only 35-44 year-olds because, although dental caries date was available to all age groups, the periodontal attachment loss was only measured among the adults and the elderly and the high prevalence of edentulism in the latter group poses concerns about bias in analysis of periodontal outcomes. The sample size for the chosen age bracket was 13,405 subjects clustered in 250 municipalities. Among these individuals, who answered the questionnaire, there were 27 with missing values in the dental exam and 426 in the periodontal exam. Due to missing values in one or more covariates (Tables 1 and 2), multivariate analysis for edentulism included 13,179 subjects. Analyses of dental caries and periodontal diseases (CAL) further excluded 1,224 edentulous subjects who were not at risk of developing such diseases. Analysis of bleeding and calculus excluded subjects with more than $3 \mathrm{~mm}$ of CAL ( $\mathrm{n}=4,085)$ and edentulous $(\mathrm{n}=1,224)$, as they are not at risk for gingivitis.

Around 2,000 examiners across the country were trained according to World Health Organization (WHO) criteria 29 in groups of five dentists, and the training continued until examiners reached acceptable values for intra- and inter- examiner agreement, measured by kappa coefficient. Data collection included clinical oral exams and a questionnaire on socio-demographic characteristics, access, and use of dental services. Every person in the household who matched the study's age groups was interviewed.

\section{Outcomes and covariates}

Two outcomes were obtained from the DMFT index, which measures the severity of dental caries (number of Decayed, Missing or Filled Teeth). The other two outcomes were derived from the periodontal Clinical Attachment Loss measure (CAL) and the Community Periodontal Index (CPI). The first outcome was edentulism (Number of missing teeth, MT = 32) and the second was the number of untreated (cavitated) dental caries (DT). The third outcome was having at least one tooth with more than $8 \mathrm{~mm}$ of periodontal attachment loss (CPI probe score > 2). The fourth was defined using the CPI index; we considered a case of gingivitis to be those with at least one tooth with bleeding, with or without dental calculus (CPI scores 1 and 2) only among those with $\mathrm{CAL} \leq 3 \mathrm{~mm}$ (score 0 in CPI probe). Carrying out an analysis of gingivitis among those with $\leq 3 \mathrm{~mm}$ of attachment loss allowed us to avoid mixing periodontitis with gingival bleeding.

The main exposures of interest were per capita municipal income and municipal income inequality (Gini coefficient). All ecological variables were obtained from the 1991 and 2000 census using specific software developed by the Regional Office of the United Nations Development Programme in Brazil. To assess cumulative exposure to income inequality, we calculated the mean Gini coefficient in 1991 and 2000. The Gini varies from 0 to 1 , but we multiplied its values by 100 in the present analysis.

We considered the following to be potential confounding factors in the multivariate analysis: sex, age, place of residence (rural/urban), time since last dental visit (four categories), equivalized income and municipal per capita income. Equivalized monthly household income was calculated by dividing total monthly disposable household income by the square root of the number of residents in the house 30 . Equivalized income was introduced in the adjusted models, as it is considered a compositional confounder. We are aware that it may be overadjusted 5 , if it is believed to be one of the mechanisms by which Gini may act, so crude and adjusted results were presented. 
Table 1

Mean number of untreated dental caries per person with standard deviation (SD) and prevalence of edentulism according to the main variables in the study in a sample of Brazilians, 2002.

\begin{tabular}{|c|c|c|c|c|c|c|c|c|}
\hline & \multicolumn{4}{|c|}{ Untreated dental caries } & \multicolumn{4}{|c|}{ Edentulism } \\
\hline & $\mathrm{n}$ & Mean & SD & p-value * & $\mathrm{n}$ & Cases & $\%$ & $\mathrm{p}$-value ** \\
\hline \multicolumn{9}{|l|}{ Age (years) $* \star \star$} \\
\hline $35-36$ & 3,485 & 3.22 & 3.86 & $<0.02$ & 3,654 & 169 & 4.6 & $<0.001$ \\
\hline $37-38$ & 2,339 & 3.20 & 4.01 & & 2,484 & 145 & 5.8 & \\
\hline $39-40$ & 2,093 & 2.78 & 3.56 & & 2,297 & 204 & 8.9 & \\
\hline $41-42$ & 1,795 & 2.59 & 3.38 & & 2,033 & 238 & 11.7 & \\
\hline $43-44$ & 2,442 & 2.75 & 3.75 & & 2,910 & 468 & 16.1 & \\
\hline \multicolumn{9}{|l|}{ Sex } \\
\hline Male & 4,097 & 3.45 & 4.05 & $<0.001$ & 4,333 & 236 & 5.5 & $<0.001$ \\
\hline Female & 8,057 & 2.70 & 3.57 & & 9,045 & 988 & 10.9 & \\
\hline \multicolumn{9}{|l|}{ Place of residence } \\
\hline Urban & 10,750 & 2.88 & 3.70 & $<0.001$ & 11,804 & 1,054 & 8.9 & 0.02 \\
\hline Rural & 1,396 & 3.49 & 4.14 & & 1,565 & 169 & 10.8 & \\
\hline Missing & 8 & 2.38 & 3.07 & & 9 & 1 & 11.1 & \\
\hline \multicolumn{9}{|l|}{ Last dental visit } \\
\hline Less than 1 year & 4,836 & 2.14 & 2.98 & $<0.001$ & 5,017 & 181 & 3.6 & $<0.001$ \\
\hline 1 to 2 years & 2,834 & 2.72 & 3.42 & & 2,993 & 159 & 5.3 & \\
\hline 3 or + & 4,028 & 3.78 & 4.19 & & 4,886 & 858 & 17.6 & \\
\hline Never & 327 & 6.78 & 5.88 & & 346 & 19 & 5.5 & \\
\hline Missing & 129 & 3.11 & 4.26 & & 136 & 7 & 5.2 & \\
\hline \multicolumn{9}{|c|}{ Household income (minimum wage) } \\
\hline Up to $1 / 2$ & 2,522 & 4.26 & 4.53 & $<0.001$ & 2,808 & 286 & 10.2 & $<0.001$ \\
\hline $1 / 2$ to 1 & 3,275 & 3.39 & 3.94 & & 3,677 & 402 & 10.9 & \\
\hline 1 to 2 & 3,426 & 2.57 & 3.32 & & 3,784 & 358 & 9.5 & \\
\hline 2 to 3 & 1,352 & 2.07 & 2.83 & & 1,453 & 101 & 7.0 & \\
\hline+3 & 1,483 & 1.48 & 2.58 & & 1,553 & 70 & 4.5 & \\
\hline Missing & 96 & 2.72 & 3.06 & & 103 & 7 & 6.8 & \\
\hline \multicolumn{9}{|c|}{ Municipal income $2000 * \star \star$} \\
\hline 1 Quartil (cities = 62) & 2,912 & 3.76 & 4.29 & $<0.001$ & 3,258 & 346 & 10.6 & $<0.001$ \\
\hline 2 Quartil (cities = 62) & 2,989 & 2.98 & 3.69 & & 3,334 & 345 & 10.4 & \\
\hline 3 Quartil (cities = 62) & 3,117 & 2.95 & 3.78 & & 3,418 & 301 & 8.8 & \\
\hline 4 Quartil (cities = 63) & 3,136 & 2.19 & 3.04 & & 3,368 & 232 & 6.9 & \\
\hline \multicolumn{9}{|l|}{ Gini 2000 *** } \\
\hline 1 Quartil (cities = 71) & 3,685 & 2.58 & 3.56 & $<0.001$ & 4,031 & 346 & 8.6 & 0.48 \\
\hline 2 Quartil (cities = 62) & 2,955 & 2.75 & 3.49 & & 3,258 & 303 & 9.3 & \\
\hline 3 Quartil (cities $=61$ ) & 2,856 & 3.32 & 3.98 & & 3,179 & 323 & 10.2 & \\
\hline 4 Quartil (cities $=55$ ) & 2,658 & 3.31 & 3.98 & & 2,910 & 252 & 8.7 & \\
\hline \multicolumn{9}{|l|}{ Gini $1991 * \star \star$} \\
\hline 1 Quartil (cities $=68)$ & 3,550 & 2.71 & 3.56 & 0.20 & 3,925 & 375 & 9.6 & 0.55 \\
\hline 2 Quartil (cities = 67) & 3,042 & 3.31 & 4.08 & & 3,329 & 287 & 8.6 & \\
\hline 3 Quartil (cities $=64$ ) & 2,973 & 2.84 & 3.68 & & 3,283 & 310 & 9.4 & \\
\hline 4 Quartil (cities $=50$ ) & 2,589 & 2.99 & 3.69 & & 2,841 & 252 & 8.9 & \\
\hline Total & 12,154 & 2.95 & 3.76 & & 13,378 & 1,224 & 9.2 & \\
\hline
\end{tabular}

* Test for trends in ordered variables obtained from multilevel negative binomial regression (excluding the missing category);

** Chi-square or chi-square for trends in ordered variables (excluding the missing category);

*** For the sake of presenting the data in a clear manner these variables were categorized; however, they were analysed as continuous. The groups are distributed evenly in true quartiles because some cities had the same Gini value. 
Prevalence of periodontal attachment loss > 8mm (CAL) and gingivitis according to the main variables in the study in a sample of Brazilians, 2002.

\begin{tabular}{|c|c|c|c|c|c|c|c|c|}
\hline & \multicolumn{4}{|c|}{ At least one site with CAL $>8 \mathrm{~mm}$} & \multicolumn{4}{|c|}{ Bleeding or dental calculus } \\
\hline & $\mathrm{n}$ & Cases & $\%$ & p-value * & $\mathrm{n}$ & Cases & $\%$ & $\mathrm{p}$-value ** \\
\hline \multicolumn{9}{|l|}{ Age (years) *** } \\
\hline $35-36$ & 3,381 & 89 & 2.6 & $<0.001$ & 2,460 & 1,588 & 64.6 & 0.03 \\
\hline $37-38$ & 2,266 & 81 & 3.6 & & 1,533 & 1,026 & 66.9 & \\
\hline $39-40$ & 2,034 & 75 & 3.7 & & 1,325 & 894 & 67.5 & \\
\hline $41-42$ & 1,723 & 77 & 4.5 & & 1,083 & 734 & 67.8 & \\
\hline $43-44$ & 2,351 & 130 & 5.5 & & 1,365 & 924 & 67.7 & \\
\hline \multicolumn{9}{|l|}{ Sex } \\
\hline Male & 3,988 & 214 & 5.4 & $<0.001$ & 2,392 & 1,655 & 69.2 & $<0.001$ \\
\hline Female & 7,767 & 238 & 3.1 & & 5,374 & 3,511 & 65.3 & \\
\hline \multicolumn{9}{|l|}{ Place of residence } \\
\hline Urban & 10,399 & 386 & 3.7 & 0.05 & 6,981 & 4,578 & 65.6 & $<0.001$ \\
\hline Rural & 1,348 & 66 & 4.9 & & 780 & 584 & 74.9 & \\
\hline Missing & 8 & - & 0.0 & & 5 & 4 & 80.0 & \\
\hline \multicolumn{9}{|l|}{ Last dental visit } \\
\hline Less than 1 year & 4,716 & 140 & 3.0 & $<0.001$ & 3,272 & 1,954 & 59.7 & $<0.001$ \\
\hline 1 to 2 years & 2,746 & 110 & 4.0 & & 1,856 & 1,253 & 67.5 & \\
\hline 3 or + & 3,855 & 181 & 4.7 & & 2,383 & 1,780 & 74.7 & \\
\hline Never & 319 & 18 & 5.6 & & 178 & 129 & 72.5 & \\
\hline Missing & 119 & 3 & 2.5 & & 77 & 50 & 64.9 & \\
\hline \multicolumn{9}{|c|}{ Household income (minimum wage) } \\
\hline Up to1/2 & 2,400 & 111 & 4.6 & $<0.001$ & 1,466 & 1,099 & 75.0 & $<0.001$ \\
\hline $1 / 2$ to 1 & 3,179 & 135 & 4.3 & & 2,027 & 1,436 & 70.8 & \\
\hline 1 to 2 & 3,304 & 125 & 3.8 & & 2,211 & 1,434 & 64.9 & \\
\hline 2 to 3 & 1,316 & 43 & 3.3 & & 904 & 548 & 60.6 & \\
\hline+3 & 1,466 & 36 & 2.5 & & 1,100 & 612 & 55.6 & \\
\hline Missing & 90 & 2 & 2.2 & & 58 & 37 & 63.8 & \\
\hline \multicolumn{9}{|c|}{ Municipal income 2000 *** } \\
\hline 1 Quartil (cities = 62) & 2,818 & 103 & 3.7 & 0.31 & 1,805 & 1,377 & 76.3 & $<0.001$ \\
\hline 2 Quartil (cities = 62) & 2,877 & 126 & 4.4 & & 1,871 & 1,273 & 68.0 & \\
\hline 3 Quartil (cities = 62) & 3,006 & 125 & 4.2 & & 2,012 & 1,203 & 59.8 & \\
\hline 4 Quartil (cities $=63$ ) & 3,054 & 98 & 3.2 & & 2,078 & 1,313 & 63.2 & \\
\hline \multicolumn{9}{|l|}{ Gini $2000 * * *$} \\
\hline 1 Quartil (cities $=71$ ) & 3,583 & 132 & 3.7 & 0.95 & 2,357 & 1,553 & 65.9 & 0.11 \\
\hline 2 Quartil (cities = 62) & 2,856 & 116 & 4.1 & & 1,799 & 1,199 & 66.7 & \\
\hline 3 Quartil (cities $=61$ ) & 2,743 & 109 & 4.0 & & 1,942 & 1,257 & 64.7 & \\
\hline 4 Quartil (cities $=55$ ) & 2,573 & 95 & 3.7 & & 1,668 & 1,157 & 69.4 & \\
\hline \multicolumn{9}{|l|}{ Gini 1991 *** } \\
\hline 1 Quartil (cities = 68) & 3,441 & 121 & 3.5 & 0.84 & 2,207 & 1,462 & 66.2 & $<0.001$ \\
\hline 2 Quartil (cities $=67$ ) & 2,923 & 141 & 4.8 & & 1,921 & 1,385 & 72.1 & \\
\hline 3 Quartil (cities $=64)$ & 2,879 & 92 & 3.2 & & 1,957 & 1,239 & 63.3 & \\
\hline 4 Quartil (cities $=50)$ & 2,512 & 98 & 3.9 & & 1,681 & 1,080 & 64.3 & \\
\hline Total & 11,755 & 452 & 3.9 & & 7,766 & 5,166 & 66.5 & \\
\hline
\end{tabular}

* Test for trends in ordered variables obtained from multilevel negative binomial regression (excluding the missing category);

** Chi-square or chi-square for trends in ordered variables (excluding the missing category);

*** For the sake of presenting the data in a clear manner these variables were categorized; however, they were analysed as continuous. 


\section{Statistical analysis}

Multilevel regressions with random intercept were performed using MLwiN 2.02 (Centre for Multilevel Modelling; http://www.bristol.ac.uk/ $\mathrm{cmm} / \mathrm{software} / \mathrm{mlwin} /$ ). Individuals were assigned as first-level units grouped into municipalities, the second-level units. For binary outcomes such as edentulism, we fitted a multilevel logistic regression. For the counting outcome, such as number of untreated dental caries, we fitted a Negative Binomial model with log link using the natural log of the remaining teeth as the offset variable. Negative Binomial is an alternative for Poisson regression in the presence of overdispersion of the mean and produce rate ratios (or mean ratios) when coefficients are exponentiated. Coefficients were estimated using Penalized Quasi-Likelihood (PQL) with the second-order Taylor expansion procedure. Goodness of fit of estimated models was assessed using Akaike's Information Criteria (AIC) corrected for differences in sample size. The lower the AIC value the better the fit of the model. Unadjusted pseudo-R2 was calculated according to Snijders \& Bosker 31 . We also calculated the Variance Partition Coefficient (VPC) according to method D as described by Goldstein et al. 32. Other analyses were performed in Stata 9.2 (Stata Corp., College Station, USA).

\section{Results}

The mean number of untreated dental caries was $2.9(\min =0$, median $=2$, $\max =29$, interquartile rage from 2 to 4 ) and the prevalence of edentulism, severe periodontal attachment loss and gingival bleeding was $9.2 \%, 3.9 \%$ and $66.5 \%$, respectively (Tables 1 and 2). Bivariate analysis showed that these outcomes were associated with socioeconomic variables at an individual level, but only untreated dental caries was associated with income inequality. Evaluation of possible sampling bias due to response rate was performed in a sensitivity analysis (data not presented), which showed that this is an unlikely cause of bias in our associations. Other descriptive data on this sample can be found elsewhere. As a sensitivity analysis, we used as alternative outcomes: the presence of 20 teeth (instead of edentulism); clinical attachment loss $>5 \mathrm{~mm}$ (instead of $>8 \mathrm{~mm})$. Results remained unchanged (not shown); therefore we maintained the use of our previous outcomes.

The correlation between municipal per capita income in 1991 and 2000 was over $r=+0.95$, so we excluded the 1991 municipal income from the analyses to avoid collinearity. Between 1991 and 2000 the Gini coefficient changed less than \pm 1 point in $16.9 \%$ of Brazilian municipalities, increased more than 10 points in $8.5 \%$ and decreased more than 10 points in $3 \%$. Municipal per capita income was higher in 2000 than in 1991 by more than $\mathrm{R} \$ 50$ in $52.2 \%$ of the municipalities, while in $6.4 \%$ income had decreased. Results for the whole country and for the survey sample were similar.

In the multiple regression models, equivalized income was the variable that changed the Gini effect most. For example, it reduced the Gini rate ratio for decayed caries from 1.21 to 1.14 . However, all potential confounding variables were kept in the model regardless of their $p$-value or whether they changed the Gini effect.

Edentulism showed a weak relation to income inequality, and all confidence intervals included the null value (Table 3 ). In the empty model, the proportion of variance attributable to the second level (VPC) was $10.5 \%$. Among the models tested, the adjusted model without any Gini coefficient yielded the lowest AIC (-0.293) with an unadjusted pseudo-R ${ }^{2}$ of $25.2 \%$ and a VPC of $11.3 \%$.

Every increase of ten points in Gini in 2000 was associated with an increase of 1.21 times (95\%CI: 1.09-1.33) the mean number of untreated dental caries. This association remained statistically significant after controlling for covariates and for Gini in 1991 (Table 3). Among the models presented, the best fit was found in the adjusted model of mean Gini $(1991+2000)$ and Gini 2000, with AIC of 5.076 and pseudo-R ${ }^{2}$ of $6.7 \%$. In the empty model the VPC was $9.75 \%$, and it decreased to $3.6 \%$ in the model with best fit.

None of the Gini coefficients was associated with periodontal disease, either in crude or adjusted models (Table 4). In the empty model, the variance among cities (VPC) accounted for $32.1 \%$ of the total variance of CAL and $22.4 \%$ of the variance of gingivitis. Models with income inequality performed only slightly better than alternative models without them. Concerning CAL, the model with best fit was the adjusted model with Gini 2000 and Mean 1991+2000 Gini (AIC = -1.3569). Concerning gingivitis, the adjusted model without any Gini coefficient was the best fit (AIC = 1.1135). The models with best fit did not explain much of the variance: the unadjusted pseudo-R2 was $5.6 \%$ and $3.8 \%$ for CAL and bleeding, respectively, while the respective VPC was $33 \%$ and $21.9 \%$. 
Association of cumulative (mean Gini 1991 and 2000), lagged (Gini 1991) and current (Gini 2000) income inequality with dental decay and with edentulism in 35-44 year-old Brazilians, 2002.

\begin{tabular}{|c|c|c|c|}
\hline \multirow[t]{2}{*}{ Models } & \multicolumn{3}{|c|}{ Rate ratio ( $95 \%$ confidence interval) of untreated decayed teeth } \\
\hline & Gini 2000 & Gini 1991 & Mean $(1991+2000)$ \\
\hline Crude & $1.21(1.09-1.33)$ & $1.04(0.94-1.16)$ & $1.16(1.03-1.30)$ \\
\hline Adjusted * & $1.16(1.07-1.26)$ & $1.13(1.03-1.23)$ & $1.19(1.08-1.30)$ \\
\hline Model 1 ** & $1.13(1.07-1.26)$ & $1.05(0.94-1.16)$ & \\
\hline Model $2 \star \star$ & $1.08(0.90-1.30)$ & & $1.10(0.89-1.35)$ \\
\hline \multirow[t]{2}{*}{ Models } & \multicolumn{3}{|c|}{ Odds ratio ( $95 \%$ confidence interval) of edentulism } \\
\hline & Gini 2000 & Gini 1991 & Mean $(1991+2000)$ \\
\hline Crude & $0.96(0.80-1.15)$ & $0.89(0.74-1.06)$ & $0.90(0.73-1.10)$ \\
\hline Adjusted * & $0.91(0.76-1.11)$ & $0.96(0.79-1.16)$ & $0.92(0.74-1.14)$ \\
\hline Model $1 * \star$ & $0.91(0.72-1.15)$ & $1.01(0.80-1.27)$ & \\
\hline Model 2 ** & $0.90(0.60-1.35)$ & & $1.02(0.64-1.62)$ \\
\hline
\end{tabular}

Note: odds ratio (or rate ratio) for ten-point increase in Gini coefficient. Gini was set to vary from 0 to 100.

* Each coefficient was independently adjusted by sex, age, place of residence (urban/rural), municipal per capita income in 2000, equivalized household income in 2002/2003, and time since last dental visit;

** Coefficients in the row adjusted by variables in the "Adjusted Model" and by each other.

Table 4

Association of cumulative (mean Gini 1991 and 2000), lagged (Gini 1991) and current (Gini 2000) income inequality with bleeding and with periodontal attachment loss > 8mm in 35-44 year-old Brazilians, 2002.

\begin{tabular}{|c|c|c|c|}
\hline \multirow[t]{2}{*}{ Models } & \multicolumn{3}{|c|}{ Odds ratio ( $95 \%$ confidence interval) of bleeding or dental calculus } \\
\hline & Gini 2000 & Gini 1991 & Mean $(1991+2000)$ \\
\hline Crude & $1.08(0.85-1.36)$ & $0.94(0.75-1.18)$ & $1.01(0.78-1.31)$ \\
\hline Adjusted * & $1.03(0.81-1.29)$ & $0.99(0.78-1.25)$ & $1.01(0.78-1.32)$ \\
\hline Model $1 * \star$ & $1.05(0.79-1.39)$ & $0.96(0.72-1.29)$ & \\
\hline Model 2 ** & $1.09(0.65-1.82)$ & & $0.93(0.52-1.65)$ \\
\hline \multirow[t]{2}{*}{ Models } & \multicolumn{3}{|c|}{ Odds ratio ( $95 \%$ confidence interval) of clinical attachment loss $>8 \mathrm{~mm}$} \\
\hline & Gini 2000 & Gini 1991 & Mean $(1991+2000)$ \\
\hline Crude & $1.05(0.74-1.51)$ & $0.93(0.65-1.33)$ & $0.99(0.66-1.48)$ \\
\hline Adjusted * & $0.99(0.69-1.44)$ & $0.88(0.60-1.29)$ & $0.92(0.60-1.40)$ \\
\hline Model $1 * \star$ & $1.10(0.70-1.74)$ & $0.83(0.52-1.32)$ & \\
\hline Model 2 ** & $1.33(0.59-3.04)$ & & $0.69(0.27-1.76)$ \\
\hline
\end{tabular}

Note: odds ratio for ten-point increase in Gini coefficient. Gini was set to vary from 0 to 100.

* Each coefficient was independently adjusted by sex, age, place of residence (urban/rural), municipal per capita income

in 2000, equivalized household income in 2002/2003, and time since last dental visit;

** Coefficients in the row adjusted by variables in the "Adjusted Model" and by each other. 


\section{Discussion}

In this study we confirmed the association between dental caries and income inequality reported elsewhere $33,34,35,36$. No previous studies explored lagged associations, and all used only contemporary inequality. Concerning periodontal disease, we did not confirm the findings from one ecological study that showed that more income inequality was associated with more periodontal disease 37. Furthermore, it should be emphasized that the variance attributable to the municipal level was high for periodontal disease. Although it is said that between-group variance is usually small 38 , most other studies analysed intra-city neighbourhoods whereas in the present study we evaluated much larger areas. Therefore, there are systematic differences among municipalities to be explained.

The main hypothesis of this study was that if current income inequality had an effect on current disease (untreated dental caries/gingivitis), then the cumulative exposure would be associated with a cumulative measure of the disease (edentulism/periodontal attachment loss). Furthermore, it would be unlikely to find a lagged effect without a short-term effect. In line with our hypothesis, 1991 Gini was not associated with current dental caries while contemporary Gini (in 2000) was. However, the cumulative exposure to income inequality (mean Gini $1991+2000$ ) was not associated with cumulative dental caries (edentulism). Income inequality (current, lagged or cumulative) was not associated with any periodontal outcome. One possible explanation for these non-significant findings is related to the area size; it has been postulated that such an association is more likely to be found in large areas 5,39 . However, the association between income inequality and dental caries has been reported in other Brazilian studies in areas smaller than those in the present study 33,34,35,36,37.

Some limitations of this study may help understand why cumulative Gini did not show the expected results with long-term outcomes, such as edentulism. Firstly, changes in city of residence from 1991 to 2000 could have led to a misclassification of exposure in relation to the long-term outcomes. Unfortunately, we do not have data on time of residence to confirm this assumption, and in the 2000 census around $10 \%$ of adults had been living in their current city for less than five years (Data available from http://www.sidra. ibge.gov.br). Secondly, as this is a cross-sectional study, with no individual level baseline data, temporal relationships between exposures and outcomes are based on lag time. For example, a long latency outcome cannot be temporally associated with a short-time exposure. Finally, causality is problematic not only in relation to the temporality of these relationships but also because plausible pathways from contextual variables to individual-level diseases are controversial 40 . If the association of current Gini with dental caries is not causal (Gini may be a marker of a current risk factor), then the long-term association may not appear.

Socioeconomic factors, like income inequality, are considered distal determinants of oral health 41,42 , and are thought to influence proximal determinants such as behaviours related to sugar consumption and oral hygiene (with fluoridated toothpaste) 41,42 . Periodontal disease and dental caries share a common risk factor: tooth brushing. Hence, if income inequality affected them through this factor, then an association would be expected with both outcomes. One possible explanation for such a difference is that dental caries may be more prone to prevention through non-behavioural measures (e.g. water fluoridation) than periodontal disease is. Population strategies to prevent gingivitis and adult periodontitis rely on health education and individual behaviour changes $43,44,45$. On the other hand, population strategies to prevent dental caries include factors that can be a target of public policy, broad socioeconomic development has been show to explain much of dental caries decline, including fluoridation 46 . Indeed, public policy is one of the pathways that have been proposed to explain the effects of income inequality $3,7,8$ and it has been shown that public policy explains most of the Gini effect on untreated dental caries 47 , Although public policy may have a slow implementation process, people living in municipalities with an established strong public policy commitment can benefit with no delay.

We conclude that our hypotheses were partially confirmed, as contemporary Gini was associated with current dental caries. The fact that the hypothesis was not confirmed regarding periodontal disease suggests that the postulated mechanism may need to be reviewed in future studies. 


\section{Resumo}

Avaliar a associação entre desigualdade de renda (Gini municipal) defasada em 2 e 11 anos com dois desfechos de curta latência (cárie dentária não tratada e gengivite) e dois de longa latência (edentulismo e perda de inserção periodontal $>8 \mathrm{~mm}$ ). Foram utilizados dados do inquérito brasileiro de saúde bucal em 2002 2003. A análise incluiu 13.405 indivíduos com idades entre 35-44 anos. Foram usados modelos de regressão multinível. Covariáveis incluídas: renda municipal per capita, renda domiciliar equivalente, idade, sexo, tempo decorrido desde a última consulta odontológica e local de residência (rural versus urbano). Estimativas brutas mostraram que apenas cárie dental não tratada estava associada ao Gini (atual e defasado no tempo), mas em modelos ajustados apenas Gini atual manteve uma relação significativa com razão de 1,19 (IC95\%: 1,09-1,30) para cada dez pontos de aumento no coeficiente de Gini. Concluímos que o Gini defasado no tempo não mostrou associação com saúde bucal e o Gini atual esteve associado com cárie dentária, mas não com doença periodontal.

Doenças Periodontais; Cárie Dentária; Iniquidade Social

\section{Contributors}

R. K. Celeste developed the study hypotheses, carried out the data analysis and wrote a first draft. J. Fritzell revised the text, data analysis and interpretations of study results. P. Nadanovsky revised the text, data analysis and interpretations of study results.

\section{Acknowlegments}

The authors collectively acknowledge support from the Institutional Grants Programme of the Swedish Foundation for International Cooperation in Research and Higher Education (STINT IG 2007-2070).

\section{References}

1. Lynch J, Smith GD. Commentary: Income inequality and health: the end of the story? Int J Epidemiol 2002; 31:549-51.

2. Marmot M, Wilkinson RG. Psychosocial and material pathways in the relation between income and health: a response to Lynch et al. BMJ 2001; 322:1233-6

3. Kawachi I, Kennedy BP. Income inequality and health: pathways and mechanisms. Health Serv Res 1999; 34(1 Pt 2):215-27.

4. Wagstaff A, van Doorslaer E. Income inequality and health: what does the literature tell us? Annu Rev Public Health 2000; 21:543-67.

5. Wilkinson RG, Pickett KE. Income inequality and population health: a review and explanation of the evidence. Soc Sci Med 2006; 62:1768-84.

6. Lynch J, Smith GD, Harper S, Hillemeier M, Ross $\mathrm{N}$, Kaplan GA, et al. Is income inequality a determinant of population health? Part 1. A systematic review. Milbank Q 2004; 82:5-99.

7. Macinko JA, Shi L, Starfield B, Wulu Jr. JT. Income inequality and health: a critical review of the literature. Med Care Res Rev 2003; 60:407-52.

8. Subramanian SV, Kawachi I. Income inequality and health: what have we learned so far? Epidemiol Rev 2004; 26:78-91.
9. Subramanian SV, Kawachi I. Whose health is affected by income inequality? A multilevel interaction analysis of contemporaneous and lagged effects of state income inequality on individual self-rated health in the United States. Health Place 2006; 12:141-56.

10. Blakely TA, Kennedy BP, Glass R, Kawachi I. What is the lag time between income inequality and health status? J Epidemiol Community Health 2000; 54:318-9.

11. Subramanian SV, Blakely T, Kawachi I. Income inequality as a public health concern: where do we stand? Commentary on "Is exposure to income inequality a public health concern?”. Health Serv Res 2003; 38(1 Pt 1):153-67.

12. Mellor JM, Milyo J. Is exposure to income inequality a public health concern? Lagged effects of income inequality on individual and population health. Health Serv Res 2003; 38(1 Pt 1):137-51.

13. Macinko JA, Shi L, Starfield B. Wage inequality, the health system, and infant mortality in wealthy industrialized countries, 1970-1996. Soc Sci Med 2004; 58:279-92.

14. Mayer SE, Sarin A. Some mechanisms linking economic inequality and infant mortality. Soc Sci Med 2005; 60:439-55. 
15. Hsieh C-C, Pugh MD. Poverty, income inequality, and violent crime: a meta-analysis of recent aggregate data studies. Crim Justice Rev 1993; 18:182202.

16. Celeste RK, Nadanovsky P, Ponce de Leon AC, Fritzell J. The individual and contextual pathways between oral health and income inequality in Brazilian adolescents and adults. Soc Sci Med 2009; 69:1468-75.

17. Sheiham A, Nicolau B. Evaluation of social and psychological factors in periodontal disease. Periodontol 2000 2005; 39:118-31.

18. Peruzzo DC, Benatti BB, Ambrosano GM, Nogueira-Filho GR, Sallum EA, Casati MZ, et al. A systematic review of stress and psychological factors as possible risk factors for periodontal disease. J Periodontol 2007; 78:1491-504.

19. Sanders AE, Slade GD, Turrell G, Spencer AJ, Marcenes W. Does psychological stress mediate social deprivation in tooth loss? J Dent Res 2007; 86:1166-70.

20. Rothman KJ, Greenland S, Lash TL. Modern epidemiology. $3^{\text {rd }}$ Ed. Philadelphia: Lippincott-Williams; 2008.

21. Caldas AF, Marcenes W, Sheiham A. Reasons for tooth extraction in a Brazilian population. Int Dent J 2000; 50:267-73.

22. Fejerskov O. Changing paradigms in concepts on dental caries: consequences for oral health care. Caries Res 2004; 38:182-91.

23. Arrow P. Incidence and progression of approximal carious lesions among school children in Western Australia. Aust Dent J 2007; 52:216-26.

24. Kopycka-Kedzierawski DT, Billings RJ. A longitudinal study of caries onset in initially caries-free children and baseline salivary mutans streptococci levels: a Kaplan-Meier survival analysis. Community Dent Oral Epidemiol 2004; 32:201-9.

25. Loe H, Theilade E, Jensen SB. Experimental gingivitis in man. J Periodontol 1965; 36:177-87.

26. Reddy MS, Geurs NC, Jeffcoat RL, Proskin H, Jeffcoat MK. Periodontal disease progression. J Periodontol 2000; 71:1583-90.

27. Área Técnica de Saúde Bucal, Departamento de Atenção Básica, Secretaria de Políticas de Saúde, Ministério da Saúde. Projeto SB2000: condições de saúde bucal da população brasileira no ano 2000. Manual do coordenador. Brasília: Ministério da Saúde; 2001.

28. Queiroz RC, Portela MC, Vasconcellos MTL. Pesquisa sobre as Condições de Saúde Bucal da População Brasileira (SB Brasil 2003): seus dados não produzem estimativas populacionais, mas há possibilidade de correção. Cad Saúde Pública 2009; 25:47-58.

29. World Health Organization. Oral health surveys: basic methods. $4^{\text {th }}$ Ed. Geneva: World Health Organization; 1997.

30. Atkinson AB, Rainwater L, Smeeding TM. Income distribution in OECD countries: evidence from the Luxembourg Income Study. Paris: Organisation for Economic Co-operation and Development; 1995. (Social Policy Studies, 18).

31. Snijders TAB, Bosker RJ. Multilevel analysis: an introduction to basic and advanced multilevel modeling. London: Sage Publications; 1999.
32. Goldstein H, Browne W, Rasbash J. Partitioning variation in multilevel models. Understanding Statistics 2002; 1:223-31.

33. Baldani MH, Vasconcelos AGG, Antunes JLF. Associação do índice CPO-D com indicadores sócioeconômicos e de provisão de serviços odontológicos no Estado do Paraná, Brasil. Cad Saúde Pública 2004; 20:143-52.

34. Tassinari WS, de Leon AP, Werneck GL, Faerstein E, Lopes CS, Chor D, et al. Contexto sócio-econômico e percepção da saúde bucal em uma população de adultos no Rio de Janeiro, Brasil: uma análise multinível. Cad Saúde Pública 2007; 23:127-36.

35. Pattussi MP, Marcenes W, Croucher R, Sheiham A. Social deprivation, income inequality, social cohesion and dental caries in Brazilian school children. Soc Sci Med 2001; 53:915-25.

36. Bernabe E, Sheiham A, Sabbah W. Income, income inequality, dental caries and dental care levels: an ecological study in rich countries. Caries Res 2009; 43:294-301.

37. Hobdell MH, Oliveira ER, Bautista R, Myburgh NG, Lalloo R, Narendran S, et al. Oral diseases and socio-economic status (SES). Br Dent J 2003; 194:91-6.

38. Diez Roux AV. Multilevel analysis in public health research. Annu Rev Public Health 2000; 21:171-92.

39. Fritzell J. Commentary: on form, comparability, and levels in the income and health relationship. Int J Epidemiol 2005; 34:293-4.

40. Kaufman JS. Socioeconomic context. Epidemiology 2006; 17:4-5.

41. Holst D, Schuller AA, Aleksejuniene J, Eriksen HM. Caries in populations: a theoretical, causal approach. Eur J Oral Sci 2001; 109:143-8.

42. Petersen PE. Social inequalities in dental health. Towards a theoretical explanation. Community Dent Oral Epidemiol 1990; 18:153-8.

43. Dentino AR, Kassab MM, Renner EJ. Prevention of periodontal diseases. Dent Clin North Am 2005; 49:573-94.

44. Kallio PJ. Health promotion and behavioral approaches in the prevention of periodontal disease in children and adolescents. Periodontol 2000 2001; 26:135-45.

45. Axelsson P, Albandar JM, Rams TE. Prevention and control of periodontal diseases in developing and industrialized nations. Periodontol 2000 2002; 29:235-46.

46. Nadanovsky P, Sheiham A. Relative contribution of dental services to the changes in caries levels of 12-year-old children in 18 industrialized countries in the 1970s and early 1980s. Community Dent Oral Epidemiol 1995; 23:331-9.

47. Celeste RK, Nadanovsky P. How much of the income inequality effect can be explained by public policy? Evidence from oral health in Brazil. Health Policy 2010; 97:250-8.

Submitted on $01 / \mathrm{Jul} / 2010$

Final version resubmitted on 03/Mar/2011 Approved on 29/Mar/2011 